\title{
Identification of five novel germline mutations of the MEN1 gene in Japanese multiple endocrine neoplasia type 1 (MEN1) families
}

\author{
Makoto Sato, Shuji Matsubara, Akira Miyauchi, Hidemi Ohye, Hitomi Imachi, \\ Koji Murao, Jiro Takahara
}

\begin{abstract}
Multiple endocrine neoplasia type 1 (MEN1) is an autosomal dominant disorder characterised by tumours of the parathyroid glands, the anterior pituitary, and endocrine pancreas. The MEN1 gene has recently been cloned and germline mutations have been identified in MEN1 patients in the United States, Canada, and Europe. We examined MEN1 gene mutations in MEN1 and MEN1 related cases in eight unrelated Japanese families. These families include five familial MEN1 (FMEN1), two sporadic MEN1 (SMEN1), and one familial hyperparathyroidism (FHP). Direct sequence analysis of the protein coding regions was carried out in all the probands. We identified six different heterozygous mutations in the coding region, of which five were novel, including one missense mutation (E45G) in both FMEN1 and SMEN1, three deletions (569del, 711del, and 1350del3) in FMEN1 and FHP, and two nonsense mutations (R29X and Y312X) in FMEN1 and SMEN1. Only one of these mutations (Y312X) has previously been reported. One proband with FMEN1 had no mutation in the entire exon sequence including the $5^{\prime}$ and $3^{\prime}$ untranslated regions. A restriction digestion analysis of 19 relatives from the five families showed a close correlation between the existence of the MEN1 gene mutation and disease onset. Four different polymorphisms, including two novel ones, were identified. These findings imply that a diversity of MEN1 gene mutations exists in Japanese MEN1 and MEN1 related disease, suggesting that analysis of the entire coding region of the MEN1 gene is required for genetic counselling in Japan. $(\mathcal{F}$ Med Genet 1998;35:915-919)
\end{abstract}

Keywords: MEN1; Japanese; mutation
Multiple endocrine neoplasia type 1 (MEN1) is an autosomal dominant disorder, ${ }^{1}$ the classical spectrum of which includes tumours of the parathyroid glands, the anterior pituitary, and endocrine pancreas. ${ }^{2}$ Less frequently observed associations include a foregut carcinoid, lipoma, and adrenal tumour. ${ }^{3}$ The MEN1 gene has been mapped to chromosome $11 \mathrm{q} 13$ and recently cloned. ${ }^{45}$ This gene encodes a polypeptide (menin) of 610 amino acid residues which show no homology with other functional proteins. ${ }^{5}$ A tumour suppressor role for the MEN1 gene has been suggested based on Knudson's hypothesis that hereditary cancers develop because of the inheritance of a mutated tumour suppressor gene and that a somatic mutational event involving the wild type allele of the gene leads to neoplasia. ${ }^{6}$ Indeed, chromosome 11q13 loss of heterozygosity frequently occurs in neoplasms of affected patients. ${ }^{7-9}$ Very recently, heterozygous germline mutations of the MEN1 gene have been identified in MEN1 patients in the United States and Canada ${ }^{10}$ and in Europe. ${ }^{11} \mathrm{~A}$ high prevalence (more than $90 \%$ ) of MEN1 gene mutations has been shown in these reports. Thirty-eight different mutations have been reported in the American and Canadian families and nine novel mutations in the European families. ${ }^{1011}$ The mutations are scattered through the translated exons $2,3,7,8,9$, and 10 , and are specific for each family. ${ }^{10}{ }^{11}$ Haplotype analyses showed two founder mutations (416delC and 512delC) in the American and Canadian populations. ${ }^{10}$ The diversity of these mutations indicates that MEN1 mutations, in contrast to MEN2 mutations of the RET proto-oncogene, ${ }^{12}$ are not confined to any particular functional domains. To date, germline mutations of the MEN1 gene have not been identified in Japanese MEN 1 families. We analysed eight unrelated Japanese families for germline mutations of the MEN1 gene in the present study.

\section{Material and methods} SUBJECTS

MEN1 was diagnosed if tumours affecting at least two of the three principal MEN1 related tissues were found in one subject. Familial MEN1 (FMEN1) was defined as MEN1 plus at least one relative with MEN1 related endocrinopathy. MEN1 was considered sporadic if MEN1 was diagnosed only in the proband. Familial hyperparathyroidism (FHP) was defined as primary hyperparathyroidism in two or more family members without MEN1. 
Table 2 Primer sequence for direct sequence analysis

\begin{tabular}{|c|c|c|c|}
\hline Position & Forward primer ( $5^{\prime}$ to $3^{\prime}$ ) & Reverse primer (5' to $3^{\prime}$ ) & $\begin{array}{l}\text { Size of } P C R \\
\text { product }(b p)\end{array}$ \\
\hline Exon 1 & CCGAGTCTGCAGGTAGTGCCC & $\begin{array}{l}\text { GGTGAGCTCGGGAACGTTGGTAG } \\
\text { gtctgtccagaaagcgcaccc }\end{array}$ & 904 \\
\hline Exon 2 & GACCTGGGTGCGCTTTCTGGAC & $\begin{array}{l}\text { GAGGTGAGGTTGATGATTTGGAG } \\
\text { ggtgagctcgggaacgttggtag } \\
\text { gagaccttcttcaccagctcacgg } \\
\text { cgaacctcacaaggcttacagttc }\end{array}$ & 1037 \\
\hline Exon 3-5 & $\begin{array}{l}\text { GTTGGACATAGAGGGTGTAAACAG } \\
\text { cctgttccgtggctcataactctc }\end{array}$ & $\begin{array}{l}\text { ACAGTTGACACAAAGTGAGACTGG } \\
\text { ggctcttctgtcttccttcctatg } \\
\text { ggtcccacagcaagtcaagtctgg }\end{array}$ & 1425 \\
\hline Exont $7-8$ & $\begin{array}{l}\text { CCTCAGCCAGCAGTCCTGTAGA } \\
\text { tggtgagaccccttcagaccctac }\end{array}$ & $\begin{array}{l}\text { CCATCCCTAATCCCGTACATGC } \\
\text { ggacgagggtggttggaaactg }\end{array}$ & 1028 \\
\hline Exon 9-10 & $\begin{array}{l}\text { CTGCTAAGGGGTGAGTAAGAGAC } \\
\text { gcatctgcccatcccttcggtg } \\
\text { gaagcctctgggactgtcgctg }\end{array}$ & $\begin{array}{l}\text { GGTTTGATACAGACTGTACTCGG } \\
\text { gtctgacaagcccgtggctgctg }\end{array}$ & 1071 \\
\hline Exon 10 & $\begin{array}{l}\text { GTTGGACATAGAGGGTGTAAACAG } \\
\text { caactctgagcccatgttctgcc } \\
\text { gggagcctaggaccactcapcc }\end{array}$ & TCGCGCTCCACAGGTAGGGAGC & 1226 \\
\hline
\end{tabular}

Capitals indicate the PCR primer pairs used for PCR amplification of the MEN1 gene.

Italics indicate the primers for direct sequencing.

Table 3 Primer sequence for PCR-RFLP or PCR-PIRA with restriction enzymes

\begin{tabular}{|c|c|c|c|c|c|}
\hline Forward primer ( $5^{\prime}$ to $\left.3^{\prime}\right)$ & Reverse primer ( $5^{\prime}$ to $\left.3^{\prime}\right)$ & $\begin{array}{l}\text { Size of } P C R \\
\text { product }(b p)\end{array}$ & $\begin{array}{l}\text { Restriction } \\
\text { enzyme }\end{array}$ & $\begin{array}{l}\text { Size of digests } \\
(b p)\end{array}$ & $\begin{array}{l}\text { Detected mutation } \\
\text { and } \\
\text { polymorphisms }\end{array}$ \\
\hline ttagcggaccctgggaggaggc & gagaccttcttcaccagctcacgg & 457 & DdeI & 177,280 & C195T \\
\hline ttccttggtgctggCcttcgtgg & ggacaggtcgacggcgcctc & 202 & $B s l I$ & $21,86,95$ & A244G \\
\hline catgttaaagcacagaggaccc & ccacagcaaaggccacaccggagAt & 87 & $\operatorname{HinfI}$ & 26,60 & 569del1 \\
\hline agacagctgaggtcacctggcCcg & ggctcttctgtcttccettcctatg & 212 & $B s l I$ & $27,74,111$ & 711 dell \\
\hline cctcagccagcagtcctgtaga & ggacgagggtggttggaaactg & 406 & $B f a \mathbf{I}$ & $\begin{array}{l}56,132 \\
218,350\end{array}$ & C1046G \\
\hline cctcgtccagggcacccagagc & ccctcctcccatttgcagatgcc & 103 & Fun4HI & 40,63 & 1350del3 \\
\hline gacctgggtgcgctttctggac & ggtgagctcgggaacgttggtag & 542 & SacII & 223,319 & $\mathrm{C} 2249 \mathrm{G}$ \\
\hline cctcgtccagggcacccagagc & ccctcctcccatttgcagatgGc & 103 & BsaHI & 25,78 & $\mathrm{C} 1364 \mathrm{~T}$ \\
\hline aagccagcactggacaagggc & gcccttcatcttctcactctgg & 192 & Bst71I & $26,47,119$ & G1731A \\
\hline agccctagaaacccaagcC cctc & aggtgggacctgtgctcccttgg & 128 & $B s l I$ & 25,103 & 2248 del 3 \\
\hline
\end{tabular}

RFLP: restriction fragment length polymorphism; PIRA: primer introduced restriction analysis.

Capital letters indicate a mismatched base pair.

Six of eight probands were evaluated at Kagawa Medical University Hospital and others at Kuma Hospital (Kobe). Study cases included five FMEN1 (F-1, F-2, F-4, F-5, and F-8), one FHP (F-7), and two sporadic MEN1 (F-3 and F-6) patients, as shown in table 1. All participants in this study signed an informed consent form.

AMPLIFICATION OF GENOMIC DNA

Genomic DNA was isolated from blood using a DNA Extraction Kit (Wako Pure Chemical Industries Ltd, Osaka, Japan) and amplified by the polymerase chain reaction (PCR). PCR amplification of genomic DNA (100 ng) was performed in a total volume of $25 \mu \mathrm{l}$ containing

Table 4 MEN1 gene mutations and polymorphisms in fapanese MEN1 and MEN1 related families

\begin{tabular}{lllll}
\hline Family & Mutated exon & Base change & AA change & $\begin{array}{l}\text { No of mutation } \\
\text { carriers }\end{array}$ \\
\hline F-1 & 2 & C195T & R29X & 4 (5) \\
F-2 & 2 & A244G & E45G & $7(12)$ \\
F-3 & 2 & A244G & E45G & $1(3)$ \\
F-4 & 3 & 569del1 & 184stop & $1(1)$ \\
F-5 & 3 & $\mathbf{7 1 1 d e l 1}$ & $\mathbf{2 2 3 s t o p}$ & $2(2)$ \\
F-6 & 7 & C1046G & Y312X & $1(1)$ \\
F-7 & 9 & 1350del3 & L414del & $2(2)$ \\
F-8 & No mutation detected & & \\
Polymorphisms & Intron 1 & C2249G & Non-coding & \\
& 9 & C1364T & D418D & \\
& 10 & G1731A & A541T & \\
& 10 & 2248del3 & Non-coding & \\
& & & &
\end{tabular}

AA: amino acid.

Number in parentheses indicates the total number of family members tested for the MEN1 gene mutation.

Bold type indicates the novel mutations.
$2.5 \mathrm{mmol} / 1 \mathrm{MgCl}_{2}, 0.5 \mathrm{mmol} / \mathrm{l}$ each $\mathrm{dNTP}, 2.5^{\circledR}$ $\mathrm{U}$ of Taq polymerase (Takara Shuzo Co, Osaka, $\vec{\nexists}$ Japan), PCR buffer (Takara), and $75 \mathrm{ng}$ of each 3 primer. The initial denaturation was carried? out for seven minutes at $94^{\circ} \mathrm{C}$ and was followed. by 30 cycles of denaturation at $98^{\circ} \mathrm{C}(20$ seconds), annealing and extension at $67^{\circ} \mathrm{C}$. (180 seconds), and by final extension at $72^{\circ} \mathrm{C} \bigcirc$ for 15 minutes. For mutation screening of all probands, MEN1 exons 2-10, including the corresponding splice junction regions, were amplified with four different pairs of primers as 5 listed in table 2 . For the mutation analysis of one proband $(\mathrm{F}-8)$ with no mutations in the coding region of MEN1, exons 1 and $10, \widetilde{N}$ including the $5^{\prime}$ and $3^{\prime}$ untranslated regions respectively, were amplified with two pairs of जu primers, as shown in table 2 .

DIRECT DNA SEQUENCING

The amplified exon products to be sequenced? were electrophoresed on a $1.5 \%$ agarose gelo and purified by the use of a QIA Quick Gelo Extraction Kit (QIAGEN Inc, CA). Sequenc- $\triangle$ ing was performed with the primers shown in $\frac{\mathbb{Q}}{\stackrel{0}{0}}$ table 2 using the Taq FS Dye Terminationo Cycle sequencing kit (Perkin-Elmer), and automated analysis was done with the ABI $377^{\circ}$ sequencer, as previously described. ${ }^{13}$

RESTRICTION ENDONUCLEASE ANALYSIS

Mutations were confirmed using restriction endonucleases according to the manufacturer's recommendations. Samples were electrophoresed in a $1.5 \%$ agarose gel containing 
Family $1(195 \mathrm{C} / \mathrm{T})$
A

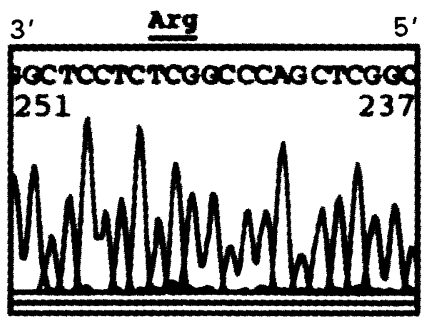

Wild type (WT)

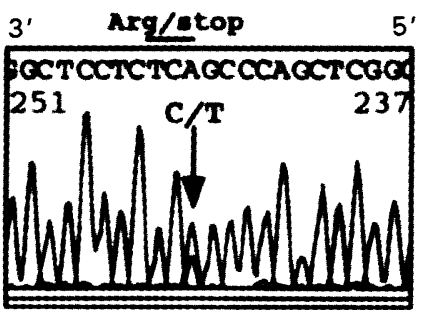

Proband (P)
B

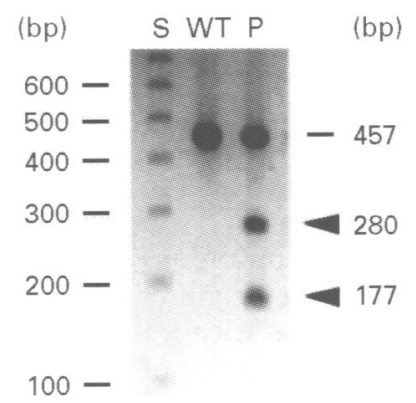

Wutant $\frac{457 \mathrm{bp}}{280 \mathrm{bp} \bigwedge_{D d e l} 177 \mathrm{bp}}$ Exon 2
Figure 1 Example of heterozygous nonsense mutation of the MEN1 gene in a proband of family 1. (A) Direct sequence analysis. The reverse sequences of wild type (WT) and the proband $(P)$ are shown. The nonsense mutation $(195 C / T)$ produces a stop codon at position 29. (B) Restriction endonuclease analysis. The mutation creates a DdeI site. Digestion with DdeI shows the presence of 280 and 177 bp fragments and the absence of 457 bp fragments in the mutant allele.
A
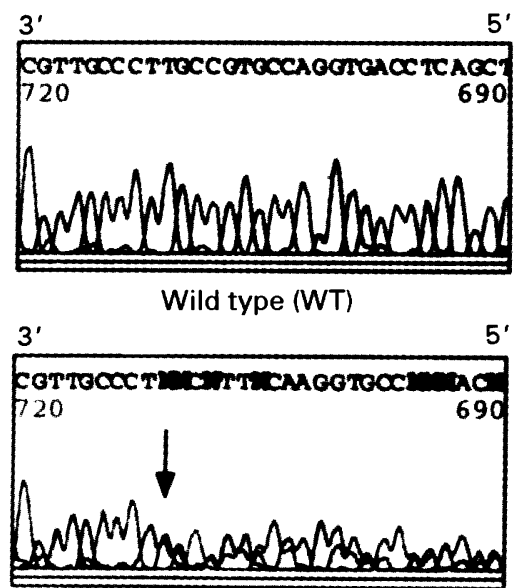

Proband (P)
Family 5 (711 A deletion)

$B$

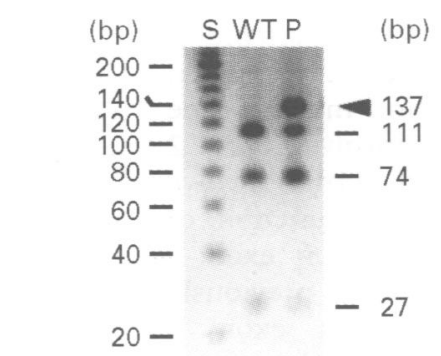

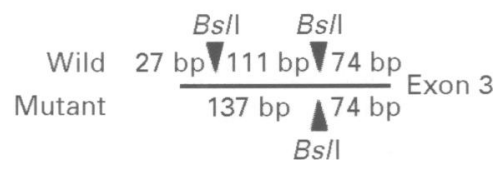

Figure 2 Example of heterozygous deletion of the MEN1 gene in a proband of family 5. (A) Direct sequence analysis. The reverse sequences of wild type (WT) and the proband (P) are shown. The mutation 711 delA produces a premature termination codon at position 223. (B) Restriction endonuclease analysis. The mutation abolishes a BslI site. Digestion with BslI shows the absence of 111 and 27 bp fragments and the presence of $137 \mathrm{bp}$ fragments in the mutant allele.

ethidium bromide and visualised by a UV transilluminator. If a mutation neither created nor abolished a restriction site for any commercially available enzymes, PCR primer introduced restriction analysis was carried out. ${ }^{14}$ Genomic DNA was obtained from the 19 relatives of MEN1 and FHP families and 50 normal subjects. PCR amplification and restriction endonuclease analysis were performed. The primers used are listed in table 3.

\section{Results}

Eight unrelated Japanese families were examined for an MEN1 germline mutation. The clinical characteristics are summarised in table
1. Five families (F-1, F-2, F-4, F-5, F-8) show clinical features of FMEN1 because family members have at least two main characteristics, such as hyperparathyroidism, anterior pituitary disease, or endocrine pancreas tumour. Two families (F-3 and F-6) may be sporadic cases of MEN1 since a family history of MEN1 is lacking or not proven. One family (F-7) is likely to be FHP with an isolated parathyroid lesion. The origin of six families was Kagawa prefecture which has a population of about one million. Two families originated from other places (Kobe and Osaka) near to Kagawa.

PCR amplification and direct sequencing were used to characterise MEN1 mutations in all coding regions and splice junctions of the MEN1 gene using genomic DNA extracted from eight probands. We detected six different germline mutations of the MEN1 gene in seven of eight families and the data are summarised in table 4. All of the mutations are heterozygous and consist of one missense mutation (E45G), three deletions (569del, 711del, and 1350del3), and two nonsense mutations (R29X and Y312X). One of the nonsense mutations (Y312X) has been previously described and the others are new. The missense mutation (E45G) was found in two unrelated families (F-2 and F-3). In the proband of family F-8, no mutation was detected in the entire exon sequence including the 5 ' and 3 ' untranslated regions.

Restriction digest analysis confirmed these mutations. For instance, in one of the nonsense mutations (C195T), the mutant sequence creates a DdeI site (CCGAG to CTGAG) and the digest showed the absence of a normal $457 \mathrm{bp}$ fragment and the presence of mutant 280 and $177 \mathrm{bp}$ fragments in the mutant allele (fig 1). In the deletion (711delA), the mutation neither creates nor abolishes a restriction site for any commercially available enzymes. In this case, PCR primer introduced restriction analysis (PIRA) was carried out. The mutant sequence abolishes a primer introduced BslI site (CCCGGCAAGGG to CCCGGCAGGG) and the digest showed the absence of normal 111 and $27 \mathrm{bp}$ fragments and the presence of mutant $137 \mathrm{bp}$ fragments in the mutant allele (fig 2). We examined 19 members of five different families with these restriction digest analyses, as shown in table 3 . Eleven affected members (F-1 three, F-2 six, F-5 one, F-7 one) showed MEN1 gene mutations in accordance with their probands. Eight unaffected members (F-1 one, F-2 five, F-3 two) had no mutations. We next examined 50 normal controls (100 normal chromosomes) by restriction analysis. The missense mutation (E45G) was not found in 100 normal chromosomes. We also detected four other mutations and two of them were previously reported as benign polymorphisms. We examined 100 normal chromosomes for these mutations and the results were $C$ to $G$ in intron 1,16 nucleotides upstream from exon 2 (69\% C, 31\% G ), D418D (C1346T) (62\% C, $38 \% \mathrm{~T}), \mathrm{A} 541 \mathrm{~T}$ (G1731A) (76\% G, 24\% A), $2248 \mathrm{del} 3$ ( $25 \% \mathrm{del}$ ). 


\section{Discussion}

We have identified six different germline mutations including five novel mutations in seven probands with MEN1 and MEN1 related disease. The mutations are scattered throughout the translated exons 2 (twice), 3 (twice), 7, and 9. This indicates that diversity of MEN1 gene mutations exists in Japanese MEN1, as has been previously reported in American and European populations. ${ }^{10} 11$ In two families (F-2 and F-3), the mutations (E45G) were identical. Although the origin of these families seems to be separate, at least for three generations, a founder effect could not be ruled out because both families originated from a small geographical area (Kagawa). Haplotype analysis is required to confirm the founder effect in these two families. Genotypephenotype correlations were not evident among the families or even within each family. In the two families with the same mutation, the MEN1 phenotypes differ. The proband of F-2 exhibits hyperparathyroidism, carcinoid tumour, and lipoma, while the proband of F-3 has an endocrine pancreas tumour associated with hyperparathyroidism. In a large family of MEN1 (F-2), the phenotypes of affected members (eight patients) differ. This might be explained, at least in part, by an anticipation phenomenon in which severity increases and age of disease onset decreases in successive generations. ${ }^{12-18}$

Five mutations including four novel mutations observed in this study predict truncation of the MEN1 gene protein, menin. One nonsense mutation (R29X) involves exon 2 and two deletions (569del and $711 \mathrm{del}$ ) involve exon 3, suggesting the loss of function of menin. The nonsense mutation on exon 7 (Y312X), which has been previously reported, ${ }^{10}$ and the deletion in exon 9 (L414del) suggest that loss of the C-terminal portion of menin is sufficient for functional inactivation. By contrast, we cannot predict a significant effect of the missense mutation (E45G) on exon 2 because of the lack of information about the function and structure of menin. The mutation is not likely to be a benign polymorphism since the mutation was not found in the restriction analysis of 100 normal chromosomes. The close correlation between this mutation and the onset of MEN1 was found in a large family (F-2). Seven patients including the proband were positive for this mutation, whereas five kindreds without the disease were negative. Thus, the missense mutation seems to be a disease associated mutation.

Interestingly, a MEN1 germline mutation was found in the proband (F-7) considered to have FHP. This observation is in disagreement with a previous report showing no mutations in five probands with FHP in the United States and Canada. ${ }^{10}$ Primary hyperparathyroidism is usually expressed at an earlier age than other lesions and the penetrance of hyperparathyroidism is very high $(95 \%)$ compared to other lesions. ${ }^{319}$ Indeed, it has been reported that two of six large families, initially reported as FHP, later showed features of FMEN $1 .^{20}$
Taken together, FHP might be considered to consist of three types of disease. One is an early stage of FMEN1 and another is a variant type of FMEN1. Both types have the MEN 10 gene mutation. The third type might be "true" FHP without the MEN1 gene mutation probably similar to that reported previously. ${ }^{1021}$ On the basis of this classification, our case appears to be a variant? because patients were relatively old and they등 had the MEN1 gene mutation.

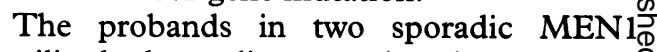
families had germline mutations in agreemen? with a previous report indicating that MEN $1^{\infty}$ germline mutations were found in eight of $1 \overrightarrow{0}$ cases of sporadic MEN1 in American and Canadian populations. ${ }^{10}$ In the sporadic caseso with features of MEN1, MEN1 can be difficult: to distinguish from independent occurrence of tumours in two or more MEN1 related endocrine tissues. Analysis of MEN1 mutations is, however, a useful diagnostic tool for any patient with sporadic MEN1. We did not find any germline mutation in one proband? with FMEN1 (F-8). Although a 3 bp deletion of the 3' untranslated region (2248del3) waso found in the MEN1 gene, this mutation 9 appeared to be a benign polymorphism. This case is definitely FMEN1 because the phenotype of the proband includes hyper- $\overrightarrow{0}$ parathyroidism, prolactinoma, and pancreatico gastrinoma and the daughter and youngero brother have the former two lesions. Agarwal ets $a l^{10}$ have also reported mutation negative MEN1 cases $(0.6 \%)$. We can not preclude theo possibility that mutations in the promoter and $\stackrel{\mathbb{Q}}{\circ}$ introns are present in these mutation negative $\overrightarrow{\vec{O}}$ MEN1 cases. We have identified four different 3 polymorphisms including two novel ones in the MEN1 gene. The distribution of one previously reported polymorphism (A541T(GCA/ACA)) differs from both ouro study $(76 \% \mathrm{G}, 24 \% \mathrm{~A})$ and the previous report? $(96 \% \mathrm{G}, 4 \% \mathrm{~A})^{10}$ suggesting an ethnicdifference in the polymorphism of the MEN1을 gene.

In conclusion, our study indicates that $a^{\bigcirc}$ diversity of MEN1 gene mutations exists in Japanese MEN1 and MEN1 related patients, as has been previously reported in westerno countries. Genetic analysis, such as directro sequencing for probands and restriction analy- N sis of relatives, are useful as diagnostic tools foro Japanese MEN1 families.

We thank Dr Yasuyoshi Iwata for the detection of the mutation: R29X in family F-1. We also thank Mrs K Yamaji for her excellent technical assistance. This study was supported in part by $\mathrm{a}$ grant from the Ministry of Education, Science and Culture of Japan and a grant (Research-on-Research) from the Kagawa $\frac{\text { Dे }}{\text { Prefecture. }}$

1 Wermer P. Genetic aspects of adenomatosis of endocrine glands. Am f Med 1954;16:363-7.

2 Ballard HS, Frame B, Hartsock RJ. Familial multiple endocrine adenoma peptic ulcer complex. Am f Med 1964;430 481-516.

3 Metz DC, Jensen RT, Bale A, et al. Multiple endocrine neo-" plasia type 1: clinical features and management. In Bilezekain JP, Levine MA, Marcus R, eds. The parathyroids. New York: Raven Press, 1994:591-646.

4 Larsson C, Skogscid B, Oberg K, et al. Multiple endocrine neoplasia type I maps to chromosome 11 and is lost in insulinoma. Nature 1988;332:85-7. 
5 Chandrasekharrapa SC, Guru SC, Manickam P, et al. Positional cloning of the gene for multiple endocrine neoplasia type 1. Science 1997;276:404-7.

6 Knudson AG. Hereditary cancer, oncogenes, and antioncogenes. Cancer Res 1985;45:1437-43.

7 Friedman E, Sakaguchi K, Bale AE, et al. Clonality of parathyroid tumors in familial multiple endocrine neoplasia type 1. N Engl f Med 1989;321:213-18.

type 1. N Engl f Med 1989;321:213-18.
8 Friedman E, De-Marco L, Gejman PV, et al. Allelic loss Friedman E, De-Marco L, Gejman PV, et al. Allelic loss
from chromosome 11 in parathyroid tumors. Cancer Res 1992;52:6804-9.

9 Bystrom C, Larsson C, Blomberg C, et al. Localization of the MEN 1 gene to a small region within chromosome $11 \mathrm{q} 13$ by deletion mapping in tumors. Proc Natl Acad Sci USA 1990;87:1968-72.

10 Agarwal SK, Kester MB, Debelenko LV, et al. Germline mutations of the MEN1 gene in familial multiple endocrine neoplasia type 1 and related states. Hum Mol Genet 1997;6:1169-75.

11 Lemmens I, Van de Ven WJM, Kas K, et al. Identification of the multiple endocrine neoplasia type 1 (MEN1) gene. Hum Mol Genet 1997;6:1177-83.

12 Mulligan LM, Kwok JB, Healey CS, et al. Germ-line mutations of the RET proto-oncogene in multiple endocrine neoplasia type 2A. Nature 1993;363:458-60

13 Yokote R, Sato M, Matsubara S, et al. Molecular cloning and gene expression of growth hormone-releasing peptide receptor in rat tissues. Peptides 1998;19:15-20.
14 Haliassos A, Chomel JC, Grandjouan S, et al. Detection of minority point mutations by modified PCR technique: a new approach for a sensitive diagnosis of tumorprogression markers. Nucleic Acids Res 1989;17:8093-9.

15 Presciuttini S, Varesco L, Sala P, et al. Age of onset in familial adenomatous polyposis: heterogeneity within families and among APC mutations. Ann Hum Genet 1994;58:331-42.

16 Heimdal $\mathrm{K}$, Olsson $\mathrm{H}$, Tretli S, et al. Familial testicular cancer in Norway and southern Sweden. Br $\mathcal{F}$ Cancer 1996;73: 964-9.

17 Horwitz M, Goode EL Jarvik GP. Anticipation in familial leukemia. Am F Hum Genet 1996;59:990-8.

18 Giraud S, Choplin H, Teh BT, et al. A large multiple endocrine neoplasia type 1 family with clinical expression suggestive of anticipation. $\mathcal{F}$ Clin Endocrinol Metab 1997;82: 3487-92.

19 Trump D, Farren B, Wooding C, et al. Clinical studies of multiple endocrine neoplasia type 1 (MEN1). $Q \mathcal{F}$ Med 1996;89:653-9.

20 Marx SJ, Attie MF, Spiegel AM, et al. Familial hypocalciuric hypercalcemia: the relation to primary parathyroid hyperplasia. N Engl f Med 1982;307:416-26.

21 Stock JL, Warth MR, Teh BT, et al. A kindred with a varian of multiple endocrine neoplasia type 1 demonstrating frequent expression of pituitary tumors but not linked to the multiple endocrine neoplasia type 1 locus on chromosome
mutent region 11q13. f Clin Endocrinol Metab 1997;82:468-92. 